\title{
THE IMPACT OF VIOLENCE AND ACKNOWLEDGEMENT OF TRAUMA ON THE MENTAL HEALTH OF BLACK CANADIANS
}

by

Karia Jones, BSW, Ryerson University, 2016

\author{
An MRP \\ presented to Ryerson University \\ in partial fulfillment of the \\ requirements for the degree of \\ Master of Social Work \\ in the Program of \\ Social Work
}

Toronto, Ontario, Canada, 2019

(C) Karia Jones 2019 


\section{AUTHOR'S DECLARATION FOR ELECTRONIC SUBMISSION OF An MRP}

I hereby declare that I am the sole author of this MRP. This is a true copy of the MRP, including any required final revisions.

I authorize Ryerson University to lend this MRP to other institutions or individuals for the purpose of scholarly research

I further authorize Ryerson University to reproduce this MRP by photocopying or by other means, in total or in part, at the request of other institutions or individuals for the purpose of scholarly research.

I understand that my MRP may be made electronically available to the public. 


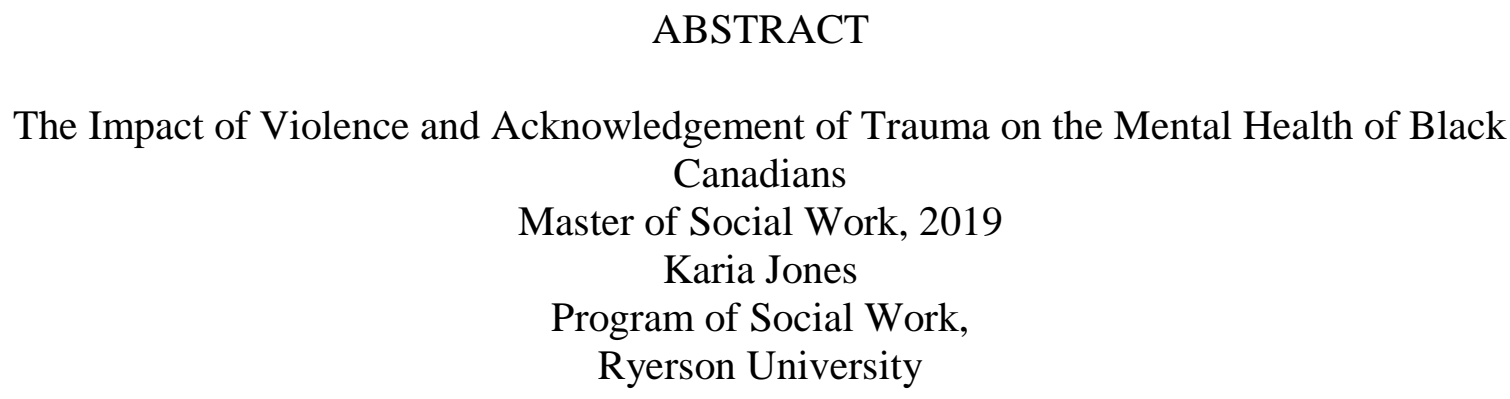

This research paper will explore the foci surrounding the Black community, particularly on violence and mental health, through a literature review of existing studies. The goal of this research is to create space for narratives that will encourage and enable participants to talk in new and potentially transgressive ways. Grounded theory used to ground the finding in the research while symbolic interactionism and Critical race theory were utilized as theoretical lens. This MRP demonstrates the various forms of violence, mental health stigma and hesitancy to access services, and resilience within Black individuals. Thus, more research and programs need to be developed in order to be able to understand the diverse levels of violence the Black community faces and how to limit the barriers they face internally and externally in regard to outside assistance. 


\section{ACKNOWLEDGEMENTS}

First, I would like to take this time to appreciate myself. It took a lot to get to this point, but I am utterly proud of my strength. I would also like to acknowledge my participants Junior, Mercy, and Kim who have taken their time to share and build with me.

I am very grateful for my partner Terado, who barely says anything, but always listens. I could not have gotten here without my MRP supervisor Gordon who was always encouraging and assuring, putting out many fires (in my head). I would like to thank my family and friends who have always supported me through my anxieties and worries. Britney, Jahnicia, and Monique, I love you.

Through it all, I have had the strength of powerful, proud, and present women behind me, holding me up and covering me with love. Nneka, Shelleena, Nicole, Janet, Amanda, and Shirley, thank you for building me so high yet always keeping me grounded. Women at the CentrE will forever be my home. 


\section{DEDICATION}

This MRP is dedicated to my future children. 


\section{TABLE OF CONTENTS}

Chapter 1: Introduction

Page \# 1

Chapter 2: Literature Review

Page \# 5

Chapter 3: Theoretical Framework

Page \# 14

Chapter 4: Methodology

Page \# 22

Chapter 5: Findings and Analysis

Page \# 27

Chapter 6: Theoretical Analysis and Critical Implications

Page \# 43

Chapter 7: Conclusion

Page \# 49

Appendices.

Page \# 51

Reference List/Bibliography

Page \# 59 


\section{LIST OF FIGURES}

Figure 1: Herbert Blumer's processes for the study of life

Page \# 15

Figure 2: Symbolic Interactionism and Grounded Theory Methodology

Page \# 16

Figure 3: Coding Framework for the MRP

Page \# 25

Figure 4: Critical Data Analysis

Page \# 43 


\section{LIST OF APPENDICES}

Appendix A - Recruitment Flyer

Appendix B - Consent Form

Appendix C - Ethics Approval Letter

Appendix D - Recruitment Poster
Page \# 51

Page \# 52

Page \# 57

Page \# 58 


\section{INTRODUCTION}

The Black community frequently suffers from vicarious trauma, physical altercations, and systematic violence, which gets internalized and normalized. These impacts are rarely questioned in order to externalize blame or to disrupt the discourse around normalcy or community mannerisms. This research paper will explore the foci surrounding the Black community, particularly on violence and mental health, through a literature review of existing studies. However, to conduct research, Hunter (2002) believes reflexivity is imperative in the research process in order to make visible what is invisible to one's own epistemology. The challenge for the researcher is to explore the effects and interconnectedness of external conditions on the process of interaction, and not merely to rely on conditions to provide a background for understanding the context of the experience (Chamberlain-Salaun, Mills, \& Usher, 2013). The goal of this research is to create space for narratives that will encourage and enable participants to talk in new and potentially transgressive ways. In order to do this, the researcher also has to take part in reflectivity and their own positionality on the topic of violence and mental health from an intersectional viewpoint.

\section{Personal Impact of Violence and Trauma}

As a Black woman born in a colonized country such as Jamaica, and raised in a colonized country such as Canada, I understand violence as holding various meanings in different contexts. The exposure of violence in my life ranges from what I have witnessed, to the impacts I have endured personally. From watching the breaking down of love ones around me from intimate partner violence, only to become a survivor to the aftermath. I have witnessed violence that is not my own, but that I continuously have to actively heal from. I have had to 
hold the trauma in order to make meaning of what was happening around me. This has led to misplacing it and mislabeling it as an individual problem. I think about the harm and violence I have done to those around me because of this internalized burden of pain, and the way in which I was not able to see those who were victims, as survivors. How, in my mind, they were never allowed to be vulnerable or at the receiving end, they were simply actors in their own lives and perpetrators in others. They were the aggressors. And even through that, I still had to take on the role of the protector. To be able to hold these traumatic impacts that somehow trickled down to me, and then go out in the world and smile; as they did.

Growing up, I was disciplined in ways that was not a simple slap on the wrist. It was the throwing of objects, the wheedling of items, and then the leaving of marks on the skin. Yet, that did not register as violence in its own right. I have feared for my life at times, scared that I would not see another day. Yet, that did not register as violence in my mind, because I had seen worse. I have witnessed the physical displays of love, anger, hate, hurt, and passion. I have seen the blood dripping from the face and the wrestling of bodies as they beat against the walls. I have heard the cries of pain as if a bullet had entered the flesh, and I have entered those spaces where I willingly laid my life on the line to protect the ones I love. And with that comes a violence of its own, which is resentment.

I felt hurt and pain, wondering why I was ever subjected to that, and then hate as I was left with the aftermath and the depression. I was left with trying to be perfect in order to not add more pressures and stress. I had developed my own anxiety, depression, and life ending thoughts. And then I had to go out in the world, where I was constantly reminded that I was at the bottom of the chain, and smile. I was not allowed to have a bad day; I was never allowed to cry. I had to stomach bullying and shaming; I had to work and prove that I was deserving of good marks and 
awards. I had to hide my pain and the pain of my loved ones. And because I was never allowed to be seen as a victim or a survivor, neither were they. It was just life.

\section{Goals of the Study}

This Major Research Paper (MRP) explored the impacts of violence on Black individuals, specifically those of Caribbean and African descent. This study aims to examine how various violent interactions (physical, emotional, spiritual, and psychological) impacts mental health. Another goal of the study is to examine and analyze the acknowledgement of trauma and the various acts of resilience by Black individuals despite the implications and challenges they have faced. It is evident in research that in order to advance the field of study, researchers must develop more creative and culturally sensitive theories and methodologies to define, measure, and understand violence in the Black community (West, 2004). Thus, the goal

for this study was to be able to gather and interview diverse individuals with multiple intersections of identities and look into their individualized forms of resilience and strategies of coping. To achieve this goal, Symbolic Interactionism and Grounded Theory have been utilized as a theoretical framework and theoretical approach in order to guide the study.

\section{Limitations of MRP}

In order to generate a theory through a grounded theoretical approach, the researcher is to conduct interviews, follow-up interviews, and consultations with participants in order to reach theoretical saturation. Due to the limitations of time and scope, this could not be achieved. Therefore, this small sample size of three participants cannot be assumed to represent all experiences around violence, trauma, and mental health of Black bodies. Although the researcher 
is not able to conduct further interviews and conversation in order to clarify concepts, Joen (2004) states that theory is an ever-developing entity rather than a perfect product. 


\section{II.LITERATURE REVIEW}

The research and articles that I reviewed on Black bodies, violence, and mental health came from various disciplines include psychology, philosophy, social sciences, medicine and health, and sociology. The literatures reviewed can be summarized using five themes. The first theme is 'racism and discrimination' which are linked to Black experiences. The second theme is 'violence' whether it is physical, psychological, or experienced vicariously. The third theme was 'PTSD and trauma' as this is the aftermath and repercussions faced by many members of the Black community. The fourth theme pertained to mental health and 'mental health services' were essential to be able to examine the stigma and perception of mental illness within the community, as well as the barriers to accessing assistance and services. Finally, the theme of 'resilience' and coping strategies as crucial tools that should always be utilized in order to explore the ways in which Black bodies continue to move through a world that is not the most encouraging.

\section{Theme 1: Racism and Discrimination}

Racial discrimination is the negative beliefs, attitudes, actions, or behaviors that are based on skin-colour or the socially constructed ideas around race. Racism, on the other hand, has been defined as an ideology of superiority followed by discriminatory or prejudicial behavior within an individual, institutional, or cultural domain (Pieterse, Nevile, Todd, \& Carter, 2012). Accordingly, the understanding of how racism and discrimination impact the lives of Black folks are essential, crucial, and fundamental to working with or within the Black community.

In regard to violence, Watkins, Walker, and Griffith (2010) stated that the cultural context of race and racism plays an important role in violence exhibited by Black males, especially when they have been racially profiled. In relation to racism and discrimination, stigma 
occurs when socially undesirable characteristics become linked with stereotypes about a class of individuals, resulting in social distance from and discrimination towards labeled individuals (Alvidrez, Snowden, \& Kaiser, 2008; Watkins et al., 2010).

Furthermore, racism and discrimination are psychosocial stressors, which result in deprived mental health and higher rates of major depression and anxiety (Pachter, Caldwell, Jackson, \& Bernstein, 2017). Numerous studies have linked reports of racial discrimination to negative psychological, physiological, and behavioral outcomes in Black individuals. It threatens mental health, self-esteem, and academic motivations for Black adolescents and is a strong risk factor for violent behaviors in Black adults (Brown \& Tylka, 2010).

Consequently, discrimination should be seen as a psychological stressor that has the potential to become toxic. Research shows that Black individuals from the Caribbean and Africa do not defer in their interpretation and reaction to discrimination. This illustrates and demonstrates that racism and discrimination is strongly based on skin-colour which impacts all those who appear Black (Pachter, Caldwell, Jackson, \& Bernstein, 2017). Further studies show that the relationship between perceived racism and reported depression and anxiety is quite robust, providing an important reminder that experiences of racism may play an important role in the health disparities phenomenon (Bonnie \& Pon, 2016; Smith, 2015). According to Pieterse, Nevile, Todd, \& Carter (2012), not only are racism and discrimination inversely associated with poor mental health and wellbeing, but it should be part of the standard intake or assessment protocol when working with Black individuals and families due to its overwhelming impact (Bonnie \& Pon, 2015; Watkins, Walker, \& Griffith, 2010). 


\section{Theme 2: Violence}

Smith and Patton (2016) examined how rigorous disadvantages within Black communities' places young Black men at a disproportionate risk for exposure to violence and trauma. Violence is one of the predominant traumatic events affecting the lives of Black youths and their communities, as well as poverty and various health disparities (Smith \& Patton, 2016). Consequently, poverty, discrimination, and compromised educational and employment opportunities contribute to the risk of experiencing and witnessing violence (Paxton, Robinson, Shah, \& Schoeny, 2004). Paxton et al. (2004) examined how violence was a salient and normative aspect in the lives of Black youths, especially in those who witnessed the act of violence.

Black youths between ages 12 and 24 years are more likely to be victims of violent crimes such as homicide or the witnessing of violent crimes (reference?). Subsequently, chronic exposure to violence has been linked to adverse psychological statuses such as depression, anxiety, and suicidal ideations. In addition, feelings of loss, stress, and isolation associated with chronic and acute violence may manifest as symptoms of post-traumatic stress (Paxton et al., 2004). Interestingly, youths who witnessed violence, but had not experienced violence, demonstrated an inverse relationship between violence exposure and depressive symptomology as a development of adaptive coping mechanisms (Paxton et al., 2004).

Nonetheless, to further interrupt the cycle of violence and to facilitate healing, providing Black individuals with the opportunity to address experiences of loss and grief in order to prevent adverse mental health and behavioral consequences is essential (Smith, 2015). As stated by Paxton et al. (2004), exposure to violence is a salient and normative aspect of the life of Black individuals. Growing up in contexts of long-term risk in terms of how often or frequent, and 
when in relation to developmental timing, the traumatic loss of death occurs across the life course. It may also produce varying developmental implications through adverse mental and behavioral health consequences (Smith, 2015).

In regard to violence and the intersectionality of gender, Black women report higher rates of intimate partner violence in comparison to ? (IPV), as race is often proxy for social class and other structural inequalities (West, 2004). In fact, murder by intimate partners is the leading cause of death among young Black women between the ages of 15 and 45 years (West, 2004). Sadly, IPV is a reality for Black families and communities as a repercussion of colonization, histories of violence and enslavement, and various forms of oppression and systematic violence. The more barriers Black women face, whether in education, occupation, and income, the higher the reported rate of IPV (Lacey et al., 2016).

\section{Theme 3: PTSD and Trauma}

Post-traumatic stress disorder (PTSD) and trauma have different implications and impacts on Black individuals. According to Taylor, Nguyen, Sinkewicz, Joe, and Chatters (2012), Black folks have higher rates of generalized anxiety disorder, social anxiety disorder, PTSD, and panic disorder. Additionally, hegemonic notions of masculinity, gender socialization, and the contextual demands of toughness in economically disadvantaged contexts might constrain young Black men's abilities to discuss emotional pain connected to the traumatic loss of loved ones to violence (Smith, 2015).

To further the implications for practice, when working with Black clients the assessment of trauma should be expanded to include experiences of race-related trauma and stress (Pieterse, Nevile, Todd, \& Carter, 2012). Research now suggests that there are psychological outcomes, 
such as depression, anxiety, and PTSD, which should be looked at in the context of trauma. This is especially the case since Paxton, Robinson, Shah, \& Schoeny (2004) found that exposure to community violence among low-income Black youth is correlated to post-traumatic stress symptomatology.

In contrast, Smith and Patton (2016) stated that there are limitations in research involving the understandings of traumatic stress among young Black folks situated in contexts of chronic violence exposure. Multiple traumatic experiences for Black individuals often times consist of childhood physical and sexual abuse, community violence in the form of witnessing assaults or losing family members to homicide, and racial and sexual harassment in the workplace (West, 2004). For Black women, these traumatic experiences often compound the negative physical and psychological effects associated with partner violence, as the legacy of trauma can be multigenerational (Brown \& Tylka, 2010). Individuals who are subjected to racist incidences are more likely to develop posttraumatic responses such as powerlessness and betrayal (Brown \& Tylka, 2010).

\section{Theme 4: Mental Health Services}

Black groups are disproportionately represented within mental health services, and continue to be affected by stigma, and a lack of culturally appropriate care (Seebohm, MunnGiddings, \& Brewer, 2010; Alvidrez, Snowden, \& Kaiser, 2008; Watkins, Walker, \& Griffith, 2010). It is not surprising that many Black people do not receive adequate treatment for mental health problems, as Blacks are less likely than whites to seek help for psychiatric problems and 
are particularly under-represented in outpatient mental health settings (Alvidrez, Snowden, \& Kaiser, 2008; Watkins, Walker, \& Griffith, 2010).

The mental health services are embedded with structural and financial barriers that implicitly exclude Black bodies that are not able to access these services due to challenging circumstances and subject positioning. Moreover, Alvidrez, Snowden, \& Kaiser (2008) found that negative perceptions of mental illness appear to be greater among Blacks and other minority populations, which could be attributed to the cultural variations in the belief about causation of mental illness. Personal responsibility is often times assigned as the cause of mental illness, such as personal weakness, improper lifestyle, or moral transgressions (Brown \& Tylka, 2010).

In addition, Pieterse, Nevile, Todd, and Carter (2012) assert that when working with Black clients, the assessment of trauma should be expanded to include experiences of racerelated trauma and stress. In regards to therapeutic interventions, providing Black clients with a framework in order to understand and make sense of the psychological toll associated with exposure to racism, might also ameliorate the sense of powerlessness and shame that is often experienced by individuals who encounter various forms of race-based oppression (Pieterse, Nevile, Todd, \& Carter, 2012).

Furthermore, Black individuals still face stigma within and outside of their communities around seeking mental health services (Alvidrez, Snowden, \& Kaiser, 2008). This prohibits or often delays treatment or attendance to programs due to stigmatizing reactions from others, and through the fear of being labeled (Alvidrez, Snowden, \& Kaiser, 2008).

For Black communities, one of the biggest limitations to seeking out mental health services is the stigma of mental illness. Little to no existing research or literature looks into any aspect of stigmatization of Black mental health consumers such as how stigma is experiences and 
how it is coped with. Alvidrez, Snowden, and Kaiser (2008) stated that majority of their participants (76\%) said that stigma played a role in initially preventing them from seeking voluntary mental health treatment, either by keeping them from recognizing that they required professional help, or as a deterrent from seeking services when they realized they required help. In addition, Williams et al. (2007) advocate that there should be a growing awareness that the cultural context of those who are seeking assistance is essential and ensuring that treatment is tailored to the needs of the individual and their social context.

Thus, the delivery of mental health services should integrate cultural and contextual factors associated with the positioning of those seeking treatment. Further research needs to happen in order for service providers to become better equipped to help Black individuals who are in need of treatment to address stigma concerns keeping them from seeking assistance. Seebohm, Munn-Giddings, and Brewer (2010) called for self-organizing groups as an alternative to mental health services due to the fact that Black individuals do not receive adequate care for mental health challenges within traditional mental health services.

\section{Theme 5: Resilience}

As expected, racism, discrimination, violence, and trauma will negatively impact individual resilience. Brown and Tylka (2010) understand resilience as overcoming the negative effects of risk exposure, coping successfully with traumatic experiences, and avoiding the negative trajectories associated with risks. In fact, studies have shown that many Black adults and children are able to adapt to stressors, as some may possess qualities that make them resilient, while other could be nurtured in environments that teach them to be resilient (Brown \& Tylka, 2010). Evidently, many Black individuals are faced with numerous adversities, like 
poverty and racial hostility, yet they manage to overcome their circumstances and develop into healthy beings. Thus, given the negative social and mental health outcomes that some Black folks experience, various researchers agree that examining the resilience of the Black community is of great importance (Brown \& Tylka, 2010).

Alvidrez, Snowden, and Kaiser (2008) studied the different coping strategies identified and utilized by Black participants. These included medicalization for therapeutic disclosure, biological challenges, normalization, dis-identification, and surrounding oneself with likeminded individuals (Alvidrez, Snowden, \& Kaiser, 2008). Undeniably, the use of a resilience approach is an essential tool for mental health providers because even though racism and discrimination places Black communities at risk for psychological distress, many do not succumb to it and instead are resilient (Brown \& Tylka, 2010).

There is a lack of studies and research on coping strategies used by Black communities who have successfully navigated societal systems and the overwhelming circumstances that accompanies those 'living while Black'. This is crucial because according to Paxton, Robinson, Shah, and Schoeny (2004) communities that are able to come together create a 'buffering' effect on the levels of social resources and social support that young Black children possess. Positive and supportive relationships with parents and peers, as well as social support, have been identified as a potential protective factor for depression among adolescences (Paxton, Robinson, Shah, \& Schoeny, 2004).

Historically, there has always been a strong tradition of 'self-help' through individuals helping themselves and others. It is also seen as people helping 'their own' which has and continues to be evident through church, neighborhood, of school communities. Thus, an ethos of individual industriousness and self-determination has been strong, as it has come about as the 
refusal to accept a 'victim culture' of hopelessness and to become self-reliant in the absence of help from others (Seebohm, Munn-Giddings, \& Brewer, 2010). As a form of resilience, self-help groups emerge and develop in response to their social policy environment, where mutual support and reciprocity are the magical ingredients (Seebohm, Munn-Giddings, \& Brewer, 2010). Selfreliance and a wish for non-medical alternatives are by no means exclusive to Black communities, but the need to address the different forms in which communities come together in order to cope together (Seebohm, Munn-Giddings, \& Brewer, 2010). 


\section{THEORETICAL FRAMEWORK}

The goal of grounded theory is to develop a theory, or a way of understanding that the researcher develops (Creswell, 2018). The theory developed is "grounded" in the data (Creswell, 2018). Thus, grounded theory does not require a theoretical framework in order to guide analysis. Using the suite of grounded theory methods is often considered methodologically sufficient and due consideration is not necessarily given to a study's epistemological and ontological underpinnings (Chamberlain-Salaun, Mills, \& Usher, 2013). This concern is compounded by the fact that Glaser and Strauss, the originators of grounded theory, did not articulate the philosophical foundation of this design (Chamberlain-Salaun, Mills, \& Usher, 2013). Further, Glaser's publication states that classic grounded theory is simply a set of integrated conceptual hypotheses systematically generated to produce an inductive theory about a substantive area, effectively dismissing the need for an underpinning philosophical perspective (Chamberlain-Salaun, Mills, \& Usher, 2013).

However, according to Newman (2008), often qualitative researchers think that a theoretical perspective and lens can give useful direction to the researcher. For this research, I have decided to utilize symbolic interactionism and critical race theory as critical theoretical lens due to their compatibility to grounded theory and their added value to this study of violence and mental health on Black bodies.

\section{Symbolic Interactionism as a Theoretical Perspective}

Symbolic interactionism is an empirical social science perspective on the study of human group life and human conduct (Chamberlain-Salaun, Mills, \& Usher, 2013). George Herbert Mead, a social psychologist from Chicago sociological tradition, was credited as the founder of symbolic interactionism (Jeon, 2004). Influenced by American pragmatism, he maintained that 
human beings go through a continual process of adaptation in the constantly changing social world, and that the existence of a mind through which contemplation of a situation occurs makes this process possible (Jeon, 2004).

Herbert Blumer later advanced this theoretical perspective as a research approach (Jeon, 2004). Blumer asserts that the study of social life requires two processes:

1.

\section{Exploration} (Depiction)

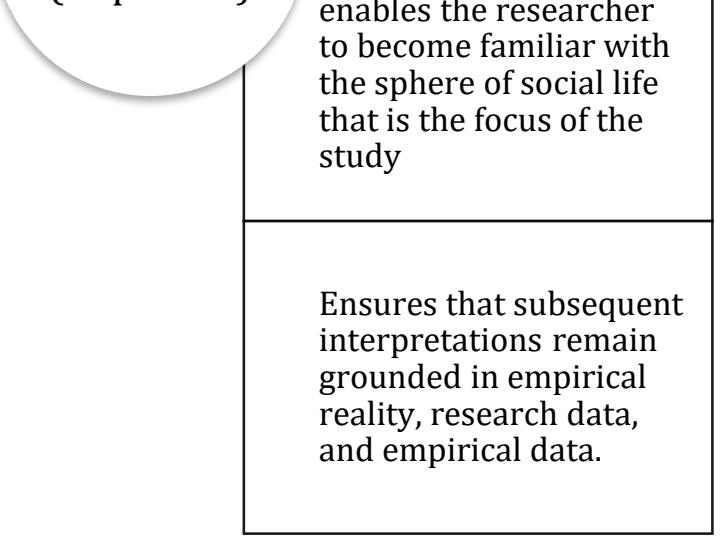

2 . Inspection (Analysis)

Establishing the validity of data analysis

The researcher conceptualizes the data and the carefully analyize the information to ensure it is grounded

Figure 1 Herbert Blumer's processes for the study of life

(Klunklin, 2006)

Thus, the researcher's role is to explicate the process by which meaning is developed and the nature of meanings that are represented in interactions between or among human beings, and that these meanings are understood through interpretations (Jeon, 2004).

\section{Symbolic Interactionism and Grounded Theory}


The theoretical framework of symbolic interactionism guides the principles of grounded theory (Klunklin, 2006). In fact, according to Chamberlain-Salaun, Mills, \& Usher (2013), grounded theory has its roots in pragmatist philosophy and symbolic interactionalist sociology.

\section{Symbolic Interactionism - Grounded Theory Methodology}

\begin{tabular}{c|c}
\hline \hline Symbolic Interactionism & Grounded Theory \\
\hline $\begin{array}{c}\text { Determination of data through disciplined observation of empirical world } \\
\text { observation }\end{array}$ & $\begin{array}{c}\text { Participant observation; interviewing, } \\
\text { document analysis; videotaping } \\
\text { Observation; interviewing guidelines; } \\
\text { theoretical sampling }\end{array}$ \\
Construction of categories & $\begin{array}{c}\text { Analytic, methodologic, personal memoing } \\
\text { Open coding; axial coding; theoretical } \\
\text { coding; properties, dimensions } \\
\text { Construction of theoretical scheme } \\
\text { Coresting of Categories } \\
\text { properties, dimensions; memos; diagrams } \\
\text { Theoretical sampling; theoretical } \\
\text { saturation; literature review; group } \\
\text { analysis; member checks }\end{array}$ \\
\hline \hline
\end{tabular}

Figure 2 Symbolic Interactionism and Grounded Theory Methodology

(Klunklin, 2006)

Utilizing the connection and relationship between Grounded theory and symbolic interactionism, I applied Chamberlain-Salaun, Mills, \& Usher (2013)'s 'meaning', 'action and interaction', and 'self' to the underpinnings of this study and my role as a researcher.

Meaning 
Symbolic Interactionism understands that meaning is not fixed and immutable because it is fluid, modifiable, and open to reappraisal. Thus, the process of ascribing meaning to data corresponds to the essential grounded theory methods of initial coding, intermediate coding, and constant comparative analysis. By constantly comparing data codes to codes, codes to categories, and categories to categories, I hope to interact with the data to understand "what is really going on". As a researcher, my aim is to attribute meaning to data through the development of codes, categories, and subcategories.

\section{Action and Interaction}

Non-symbolic and symbolic interactions are two forms of social interaction. Nonsymbolic interaction is a stimulus-response process in which individuals respond directly to one another's gestures or action. Interactions become symbolic when individuals interpret and define their own or another's objects and actions, and act on the basis of assigned meaning. Thus, symbolic interaction is an interpretive process that directs the actions of one doing the interpreting and conveys to the other, or to one's self, how he or she "is to act". Similarly, interacting with participants, the data, and with one's self are key activities is grounded theory research. Momoing which refers to documenting participants emotions and my own emotions during the interview can assist in establishing social worlds and codes. In fact, documenting and memoing my own emotions, feelings, and associated actions enabled me as a researcher to more fully explore and challenge my interpretations of the research data.

\section{Self}

The symbolic interactionism concept of self is a cornerstone of the conceptual structure because self is central to all social acts. The human being is an object to one's self and one's own 
actions, therefore, self is continually constituted through reflexive processes, or self-interaction. In grounded theory, self is demonstrated in the act of memoing and in developing theoretical sensitivity that the symbolic interactionist concept of self predominates.

\section{Critical Race Theory as a Theoretical Framework}

Critical race theory (CRT), as a theoretical lens, exposes the centrality of race and racism and the intersection of race and racism with other forms of subordination (Malagon, Huber, \& Velez, 2009). In the research process, CRT does not simply treat race as a variable, but rather works to understand how race and racism intersect with gender, class, sexuality, language, etc. as structural and institutional factors that impact the everyday experiences of people of color (Malagon, Huber, \& Velez, 2009). CRT critically frames race in the research process by including methodologies that expose the structural and institutional ways race and racism influence the phenomena being investigated. It is also committed to challenging race-neutral dominant ideologies such as meritocracy and colorblindness that have contributed to deficit thinking about people of color. CRT counters deficit thinking within the research process and requires critical race researchers to deeply analyze how their research instruments, many of which stem from positivist research approaches, may end up affirming the same dominant ideologies they strive to challenge in their work. Thus, CRT seeks to develop, create, and utilize research methodologies and tools that can adequately capture the lived experiences of communities. It allows researchers to move toward a form of data collection and analysis that builds from the knowledge of communities of color to reveal the ways in which race, class, gender, and other forms of oppression interact to mediate the experiences and realities of those affected by such oppression (Malagon, Huber, \& Velez, 2009). 


\section{Critical Race Theory and Grounded theory}

Malagon, Huber, and Velez (2009) stated that the grounded theory approach offers many characteristics that support CRT research methodology. The methodological strategy of grounded theory has significantly impacted qualitative research by contributing to a number of theoretical shifts for over thirty years, however, grounded theory was not developed as a methodology for collecting knowledge and building theory from the lived experiences of people of color (Malagon, Huber, \& Velez, 2009). In grounded theory, researchers seek multiple and diverse perspectives to illuminate the theoretical properties of emerging concepts in a given study. Several defining components of grounded theory support an approach that informs a CRT methodology. One of these components is the constant comparative method, allowing the researcher to make comparisons during each stage of analysis.

This method involves simultaneous engagement of data collection and analysis which is seen as a critical aspect of grounded theory. In addition, constructing analytic codes and categories from data advances theory development during each step of the process (Creswell \& Poth, 2018). Memo writing, which is essential in grounded theory, further elaborates categories, which helps to specify their properties, define relationships between categories and identify potential gaps (Creswell \& Poth, 2018). Another component of grounded theory that is attractive to the CRT researcher is sampling aimed at theory construction, instead of population representativeness. Because CRT is committed to illuminating the experiences of those who are marginalized, there is less concern with both the external validity required by traditional research methodologies and the ability to generalize the study's findings beyond the immediate study (Malagon, Huber, \& Velez, 2009). 
Drawing from various sources of knowledge, this methodological approach poses systematic, yet flexible, guidelines for collecting and analyzing qualitative data to construct theories "grounded" in the data itself. Our data analysis generates the concepts we construct in order to further our commitment to deconstructing oppressive conditions and empowering communities of color (Malagon, Huber, \& Velez, 2009). Thus, when used in partnership with a critical race framework, the researcher can utilize grounded methodology to interpret the perspectives and voices of the narratives that remain unacknowledged, invalidated, and distorted in social science research (Malagon, Huber, \& Velez, 2009).

By working to situate grounded theory within a critical race framework, the researcher can strengthen the interdisciplinary, methodological toolbox for qualitative critical race research, which seeks to build theory from the lived experiences of the researchers' informants and research collaborators (Malagon, Huber, \& Velez, 2009). In addition, by aligning grounded theory with the goals of CRT, the researcher can deliberately attempt to employ grounded theory in the research process to directly challenge previous scholarship that has distorted and erased the experiences of students of color, their families, and their communities.

Grounded theory research aims to develop substantive or formal theory, and thus a means of explaining social processes (Klunklin, 2006). Similarly, symbolic interactionism is one of the interpretivist perspectives in research and is the theory and approach for the study of individuals' action or interaction in search of portraying and understanding the process of meaning making (Jeon, 2004). In addition, CRT amplifies this process for people of colour by allowing for a consideration of intersectionality of race and gender. Not utilizing CRT in my MRP runs the risk of reproducing whiteness, especially since a critical race-grounded methodology draws from multiple disciplines to challenge white supremacy, which shapes the way research specifically, 
and society generally, understands the experiences, conditions, and outcomes of People of color (Yee, 2005). Therefore, both grounded theory, symbolic interactionism, and Critical Race Theory aims to understand the complex world of lived experiences from the point of view of those who live it (Jeon, 2004). 


\section{METHODOLOGY}

This MRP used a grounded theory qualitative research design. Qualitative research amplifies the voices of the participants and operates within an interpretive framework. This is an exploratory study in nature that focuses on the aspects of 'knowing how' violence impacts Black Canadians and their lives. By applying an exploratory study, as a researcher I am allowed to use the power of inquiry and assessment to form a thesis about what I am seeing and experiencing (Faulner \& Faulner, 2016). I am also able to utilize open-ended questions that capture participants' experiences and voices (Faulner \& Faulner, 2016). For this MRP, my goal as a researcher is to record experiences of violence and trauma from Black bodies and amplify their voices through open-ended questions.

\section{Major Research Question and Objective}

The main question of this MRP is 'what are the impacts of violence and trauma on the mental health of Black Canadians?'. The objective of this research is to explore the various forms of violence and trauma experienced by Black Canadians, their forms of resilience, resistance, and self-care. I am also interested in whether mental health services were available to, and/or accessed for support by participants.

\section{Approach Inquiry: Grounded Theory}

Grounded theory was developed in 1967 by two sociologist researchers, Barney Glaser and Anselm Strauss (Creswell \& Poth, 2018). They believed that theory should be grounded in data from the field, especially in the actions, interactions, and social process of people (Creswell \& Poth, 2018). Generally, grounded theory is an approach for generating theory that is grounded 
in and systematically derived from data, with an emphasis on the comparative method of constant, concurrent data collection and analysis (Jeon, 2004).

For my MRP, I have utilized Kathy Charmaz's (2018) constructive grounded theory approach which emphasizes diverse local worlds, multiple realities, and the complexities of perceptions and actions. In addition, it lies within the interpretive approach to qualitative research with flexible guidelines where emphasis is placed on the views, values, beliefs, feelings, assumptions, and ideologies of individuals (Creswell \& Poth, 2018). This approach was chosen based on my research question due to its applicability, the examination of relevant literature, and lack of research conducted in this area of violence, mental health, and Black Canadians. Moreover, Newman (2008) advocates that researchers from the constructivist grounded theory perspective recognize the mutual creation of knowledge by the viewer and the viewed and aim towards an interpretative understanding of participants' meaning.

\section{Recruitment and Sampling Method}

For this research, data was collected from three participants who identify as Black, having a background from either the Caribbean or Africa. They have experienced various forms of violence and trauma in their lives and are willing to share their experiences. This purposeful sampling, also called judgmental sampling, was orchestrated from predetermined characteristics in mind (Faulner \& Faulner, 2016), done in order to gather participants who are able to provide relevant data in regard to the research topic. According to Jeon (2004), the aim is to sample those people most likely to have sufficient knowledge and experience related to the topic of study.

I developed a flyer (see Appendix A) in order to recruit participants. I posted the flyer on social media platforms, specifically Facebook and Instagram. Potential participants were asked 
not to comment on the public post, but to email the researcher privately in order to participate. Moreover, I conducted direct outreach and network connections with acquaintances and community members in order to recruit participants for this research. I obtained the names and email addresses of the research participants during the recruitment process, which helped me to arrange interviews and correspondence with the participants during the research process. The objective of the study and the potential risks of the study were discussed. Participants who agreed to join the study were provided with details regarding their involvement and roles, how their identity will remain anonymous and the withdrawal process of the study. A consent letter (See Appendix B) was signed by the participant prior to interview.

\section{Data Collection and Analysis}

Data collected for this MRP was composed through semi-structured audio-recorded interviews that took approximately one hour. All interviews were conducted in the MSW (Master of Social Work) lounge at Ryerson University during the participants' available meeting time. I transcribed the interviews. By utilizing grounded theory, I used open coding to develop themes, or categories of information, using a comparative approach while analyzing transcripts

(Creswell, 2013). I have selected and utilized common themes that are supported by the data provided to the researcher by the participants to describe their experiences. I took field notes, or memoing, during the interview process, which has been used to help inform the data analysis. According to Chamberlain-Salaun, Mills, \& Usher (2013), memoing provides a means through which the researcher can make visible their internal dialogue regarding the negotiation and integration of my own and participants' perspectives. As a researcher, my goal is to be consciously aware of multiple perspectives and how perspectives influence participants', and my 
own actions and interactions will enable me to build variation into data analysis, particularly during intermediate and advanced coding (Chamberlain-Salaun, Mills, \& Usher, 2013). Thus, a diagrammatic analysis of themes and sub-themes were identified based on the mount of supporting data was created:

\section{Coding Framework for the MRP}

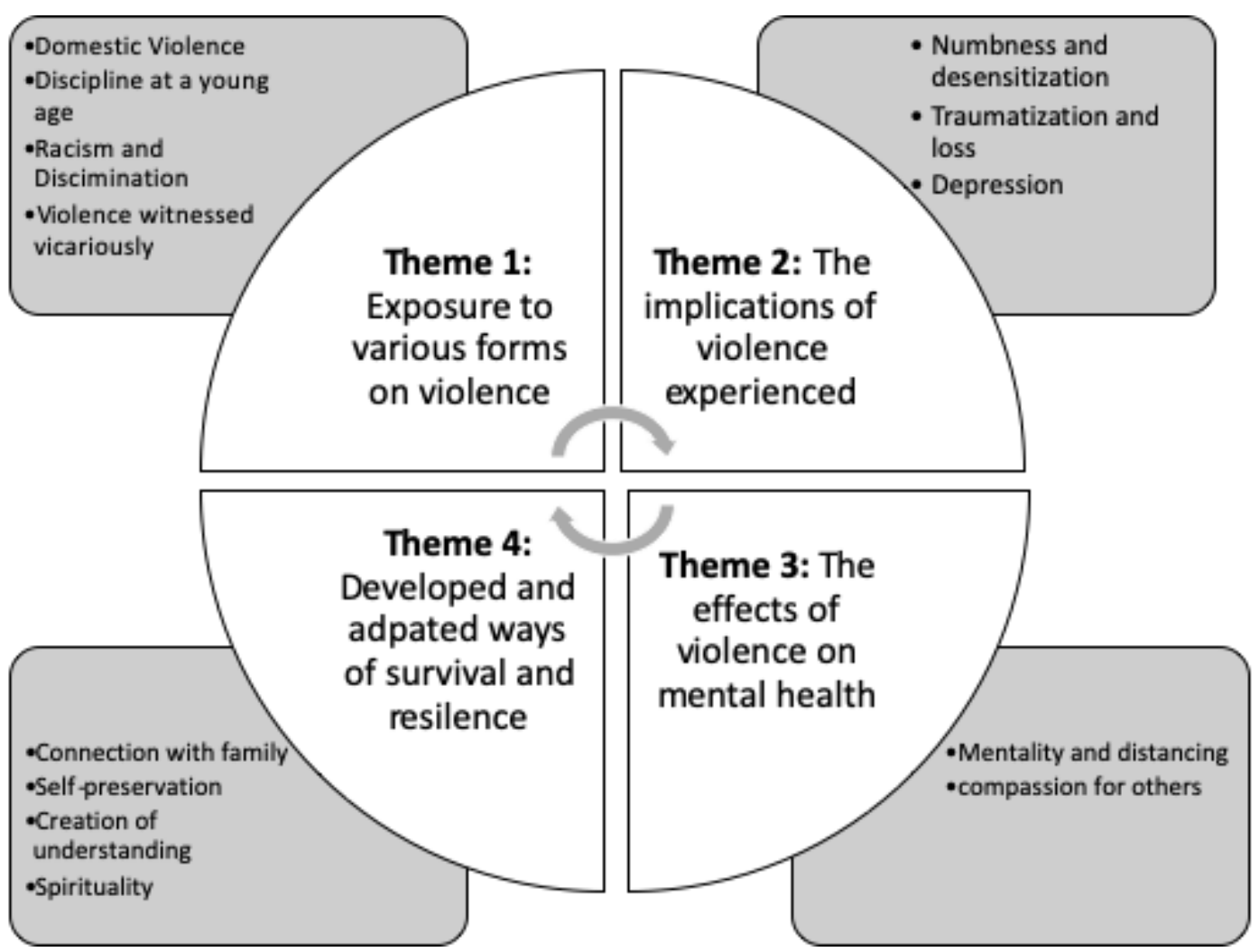

Figure 3: Coding Framework for the MRP

\section{Participants Profiles (using names given by participants)}

Mercy is a university student who values education. She was born in Kenya and lived in a refugee camp before coming to Canada at a young age. She has been in Canada for 19 years which is most of her life. She speaks of herself as "Black and beautiful. And African", 
Junior was born in Jamaica and raised there for most of his life before moving to Canada eight years ago. He refers to himself as 'an honest man' with a 'good personality', as well as 'a proud Black man.'

Kim was born in Jamaica but moved to Canada 15 years ago. She identifies herself as 'a single mother' with five children, living with the five of them. She also identified as a Black woman.

\section{Ethical Considerations}

The proposal of this study was reviewed and approved by the Ryerson Ethics Board (See Appendix C). The researcher has followed grounded theory qualitative research method in order to conduct this study systematically. There are low risks associated with this study and were minimized by protecting the personal data of the research participants and using pseudonyms. 


\section{V.FINDINGS AND ANALYSIS}

\section{Theme 1: Exposure to various forms on violence}

All three participants have expressed and discussed how violence was a critical part of growing up. Mercy was raised in Canada, while Junior and Kim were both raised in Jamaica. As most Black Canadians have either a connection to their cultural communities or raised in a different country at a young age, such as me, it is essential to understand that lived experiences have been impacted by violence. Mercy, Kim, and Junior discussed violence being present in their lives through domestic violence within the family or relationships, discipline at a young age, near death experience, racism and discrimination, and violence witnessed vicariously.

\section{Domestic Violence}

The only participant who did not speak on domestic violence was Junior; he identified as a heterosexual male. However, Mercy witnessed the ultimate consequence of domestic violence against women:

My father was an alcoholic. And so sometimes, like, he would lash out at my mom, and then I guess the ultimate form of violence had happened like when I was 11 years old, and he did kill my mom. And so, she's dead. And he's in jail right now. So, yeah. There has been some trauma. No, I wasn't there. My older brother was.

According to Bugeja et al. (2013), intimate partner violence (IPV) has been established as one of the leading causes of death among women and is often perpetrated against women by men. For Kim, IPV was a regular occurrence in her relationships on various occasions. When asked if she had ever experienced domestic abuse with her partners, she responded with the following:

Yeah. Most of my relationships. They would slap you in your mouth. They would slap you in your face. They want to push you. They want to have sex without your consent, force you to have sex, telling you "Oh, it's their body". You must have sex when you 
don't want to. They will rough you, speak like you're nothing. They will shout at you. If you talk back, they will hit you.

I have faced a lot even with my children. I face... even in Canada I had a relationship, with this person and during this relationship, he wants to be controlling. He wants to tell me how to eat, how to dress. He wants to tell me what time to work, and if I don't do it he will shout, he will lift me off the floor, like strangle. He wants to kick off my door, want to come in, I had to call the cops last time it happened, and they put a restraining order on him.

No, I've been hit in the head many times. By my baby dads, by my boyfriends. one of my baby dads would like to fight. If I talk, he hit me. If I shout, he will hit me. If I tell him I'm moving, he will kill me. So, one day I wait till he went to work. So, I just move with the children behind his back. When he come home, he sees me no more. And then when I move, a friend of mine told me, he went to all of my workplaces, searching for me."

When asked how many times she's been hit in the head:

Multiple times. I can't count. I got hit with a board, a tow-by-four, with a hammer, and I got 13 stitches. I got two chop in my head by the board so I got 13 (stitches) in one (cut) and nine in one. It cracked the skull. I got lick (hit) on my mouth, I got four stitches. I got one in my forehead, I got five stitches. I got my jawbone broken, my mouth has to close for two months. I can't eat, only drink. I had to drink through a straw.

\section{Discipline at a young age}

Discipline is referred to as getting 'beatings' or 'beat' by parents at a young age while growing up. For all participants, being beaten had various impacts on their lives within the context that they took place:

Yeah, so I guess in my household, as a form of discipline, the, like my brothers and I would get beatings so that was regular growing up, and that respect and fear was instilled into us from a young age. (Mercy)

My mother use to beat me all the time so I was scared of telling her I was getting molested by my grandfather. After I told my grandma that grandfather was touching me, she beat me. So, I didn't want to tell anyone else. (Kim)

Junior spoke of a time his father disciplined him because he did not want him hanging around his friends anymore: 
My father beat me... So my dad beat me very badly and tell me don't go with them. And two weeks after that, those two guys was dead. Only because my dad was like, on me, not to go around them... The discipline I get from that, it help me. And from that day, I never like, go around people with those stuff. I always remember. (Junior)

Discipline within the household tends to be a typical upbringing of various households.

Pate \& Gould, (2014) refers to beatings as corporal punishment which is the gratuitous intentional infliction of pain on children's bodies for the purpose of modifying behaviour. Not only did beating modify action or behaviour as stated by my participants, it also deterred Kim from speaking out about her abuse as a child in fear of being punished. Evidently, the line between corporal punishment as a disciplinary tool and abuse is thin at best, as it is common for beatings to seriously injure a child (Pate \& Gould, 2014) physically and/or psychologically.

\section{Racism and Discrimination}

Despite being born in different countries, the findings show that instances involving racism and discrimination were exclusive to the time period in which participants were residing in Canada. When asked about experience of racism and discrimination, Kim stated that "I've never been anywhere to face (racism and discrimination), only in Canada, cause where I come from, all Black peoples are there. If you cuss me I'm Black, you're Black.”

Race is only visible when you are outside of your racial group or country. In Canada where there are many different cultures and backgrounds even within the category 'Black', racism and discrimination based on skin colour or even complexion is frequent. Participants recalled both subtle and overt forms of racism yet did not seem as effected by it as they did the more physical forms of violence: 
My neighbors that I have before, they called me nigger. They were cursing me out, oh you're Black, you need to go back home, nobody knows you. Nobody cares about you. They're Indians. They're from Pakistan. (Kim)

I go to place all the while and get stuff and I noticed they don't quick to come on ask me what do I need; then people after me come in and they quick to come up to them and say... some time I have to stand up and say you didn't see me here before? ...I listen to their words carefully when they are addressing other people but when they are addressing me I see how they more like... they don't value what they say...through their action, I can see it. “ (Junior)

Personally, I wouldn't say that I have experienced much of it, because I was never involved with the justice system. But and I always strive to, like, do well, but perhaps subliminally, yes, but nothing that I can overtly recall as being like, 'Oh, I remember like, that was racist'. So maybe growing up kids would pick on you because of your skin color and stuff. Or maybe like some things a teacher said, you're like, oh, that was kind of off. But at the time, like, I wasn't able to say, that was racist, or that was like, negatively fueled. So, I can't speak to that. (Mercy)

\section{Violence witnessed vicariously}

Along with experiencing violence first hand, findings show that violence witnessed vicariously occurred just as frequently, if not more. Although Mercy only spoke to the death of her mother at the hands of father, Kim and Junior spoke to both witnessing violence, killings, and murders which happened in front of them, and also coming close to dying themselves.

Junior:

I was walking. I was walking down the road and same time this guy run out the police station and the police shoot him down right at my foot and he was like yapping and begging me to help him. I was 15 at the time. 
People come to rob people and shot people. I was about 17 at that time. They come to rob the man, them that were gambling. And one man said he not giving no money (laughs). He get shot and the guys, them walk on him.

My cousin. My cousin, when we was at the beach, and my cousin; this guy stole my cousin money, and he (cousin) take the fish gun and shot the guy straight in the center of his forehead, kill him. And the guy didn't dead but after a couple of months, he died. and he (Cousin) go to prison for 15 years because of it.

Kim:

Gun. Well, I see man with gun walking in the street. I see violence, people chopping up people. Fighting. I remember when I was small, two man when I was going to basketball...then we saw one man jump off a bus rushing a man with a cutlass and the other man had a cutlass. And he was running, running up the road... and then they started to fight. They started to chop off each other, trust me it was crazy."

I remember one time. I was 16 and washing clothes on the line and any of these bad boys down the street coming down with their guns...And when they rush through I saw the guy take out the gun from the corner of his waist and crank it like this (shows movement). I stand up. I want to pee myself...I couldn't pee myself. But my girlfriend she peed herself because that was the first time we ever saw (a gun) at the age of 16. And I couldn't run, my girlfriend couldn't run, because it was two man and if we run they would have shoot us. So, we were standing there trembling, shaking... And then when you looked the gunman rushed to the gate with him and his friend run down the street, and both of them run and then I heard (made gunshot noise) two police man were down there waiting for them. Right as they come out through the gate, the police kill one of them. So, if they never come through the gate, and then the policeman saw them, then maybe I would have died. Then my girlfriend would have died.

\section{Theme 2: The implications of violence experienced}

Through various form of violence either experienced or witnessed, participants have either experienced or suffered from traumatization, loss, and depression, or numbness and desensitization. These could be a result of exposure and impacts caused or related to the processing of situations or circumstances. This also speaks to the resilience and resistance to 
violence, and how Black bodies are constantly having to evaluate, situate, and move forward in order to 'function' within society.

\section{Depression}

Depression was a difficult emotion for my participants to situate themselves within.

When speaking on how Kim felt about the death of a friend, she stated "I sit, but its stressing. I worried but I tried not to, but I worried about it.”

When speaking on the death of her mother, Mercy stated:

It's painful. So, I guess I ... I don't say I would go through doubts of depression, but I do go through doubts during certain times of the year where, like, I don't want to say I want to kill myself, but life is very difficult. And, like, I have to, like really work on convincing myself to look at the good. And psychologically, still, emotionally, I do have difficulty trusting men, in general in my life, and growing up, like, I didn't trust Black men, because that violence did come from my father, who was a Black male. But as I've matured, like, I've had to, like retrain and like, almost face my fears. And so, yeah.

\section{Traumatization and loss}

Loss and traumatization are a powerful and everlasting impact suffered from violence on an emotional and psychological level.

Kim on trauma and loss:

I had a friend that died. I was like, two seconds I was there talking to him and laughing with him. And then after less like, two seconds, they shot him and killed him. And then like five minutes after a family (member) call me and tell me 'oh, your friend died'. I'm like what? And they say yes, he just died like five minutes ago, they come and shoot.

I was young ... around say $16-17$, so me and two girls and it was a Christmas and it was Grand Market night and we wanted to go out. Then we went downtown, but then this guy she wanted to see we never know he was wanted by the cops. The guy hold her down and wanted to rape her and she scream out and we went in, but we were young and didn't know what to do. So we're there fighting him (laughing) and then we saw his friend come in with a gun and tell us don't move, and if you do I will kill you with the 
gun. He said if you tell anyone or go to the cops I will kill you all. And from that day I was so traumatized.

Mercy spoke about trauma and loss, particularly in terms of the death of her mother which resulted in her and her four siblings ending up in the foster care system:

It was traumatic. And at the time, I just threw myself into school and doing the best that I could do. Yeah, um, I do acknowledge that I have experienced trauma.

It was horrible. They were white [foster parents] (laughs). It wasn't horrible because they were white, it was horrible because I was taking away from my family, from my community; I lost my sense of identity, the African culture, my language as well. They were white, their food tasted bad. And they didn't make any effort to get to know where we came from, and like our identity. And so, it's almost as if we had to assimilate. And I know that I definitely like while I was there, I had to play a role of being the good girl. Because I watch movies, I know that foster kids get separated and siblings and brothers, they don't see each other. So, we did everything that would be good to not get into trouble, even if it meant, not speaking out against injustices that we felt were unfair when we were living at the foster family. Because of the fear of being separated from one another and my siblings and I. I figured I can endure a few years. It's not the end of the world, as long as I'm with my brothers for the amount of time that I am with them... You feel as if you can't voice your opinion. And you can't speak to defend yourself. Because a word they like to use a lot was being disrespectful. To this day, that word (laughs) it really, it really gets to me.

A loss of identity, a loss of community, a loss of trust. A loss of home, like the sense of home, I guess, the feeling of home. And the feeling of helplessness is what I would have to say, as effective through this experience, or the violence I experienced.

\section{Numbness and Desensitization}

Speaking to the topic of loss, traumatization, and depression did not come naturally to

Junior. We can examine these different displays of emotions in terms of gender. Jackson (2018)

argues that Black men may partake in surface or deep acting, while working to evoke or suppress

particular emotions. However, Gaylord-Harden et al. (2016) found how exposure to community violence at a young age resulted in showing lower levels of emotional distress, which is a result 
of desensitization. Thus, it is essential to present Junior's own words based on the impact and consequences of violence:

When I was younger, it was more emotional to me. As soon as I get grown and I understand life and I see things keep on happening, it's not emotional anymore, and start to feel like it's life. That how things go sometimes; it's like if the person is close to me I really feel it but if they are not it's like...but people have to more...be aware of their surroundings... because a lot of times I see people get gunned down only because they are standing at the place where they are not supposed to be standing.

When asked how these experiences of violence impacted or influenced his values and how he sees himself, he responded:

It doesn't change nothing about growing up. It didn't change anything about growing up and about myself. I just see myself not being a part of those violence and I just see myself living my life straight. It makes me stronger and not doing negative things, doing positive things. And try to work for what I want in life.

\section{Theme 3: The Effects of Violence on Mental Health}

Mental health is an essential topic when we look into the impacts and consequences of violence. Unfortunately, mental health is often associated with mental illness in the Black community, especially around the mis-conceptualization of madness. According to Arthur et al. (2010), there is a huge stigma in Jamaica regarding people not treating those with mental illness as though they were human beings, rather isolating them as 'mad'. Although limited studies have been conducted to examine the stigmatization and marginalization of Black bodies outside the western gaze and colonization, it is evident that this perception still holds weight through my findings. Participants were reserved to speak on mental health but distanced themselves by association. Instead, they spoke on self-preservation and their compassion for others who require or seek help. 


\section{Mentality and Distancing}

Even with progressive conversations happening in the greater social context around

mental health, there is still a huge stigma within certain communities around requiring outside assistance or accessing services. The participants in this study developed various understanding of what it means for an individual to acquire such help, and how they support this seeking out of assistance in the case of others, but not for themselves.

Mercy was more willing and open to discuss her views on mental health in comparison to the other two participants:

I'm so happy that in this day and age, there are more progressive steps being taken so that mental health is more spoken about. Mental health is very important as much, if even more so than physical health. Because if you don't handle or, if you're unable to cope with the demons within, then the demons outside, like, will easily take over you. Like the external forces, which is why it's so important to like, take care of yourself, before you can take care of others or like to tackle the obstacles in your day, which is why I feel as if I have a lot of people can get trapped. And so, with mental health, like for me, I always think like, like, what makes me happy? What can I do that I know like, that will not make me upset.

When asked if she had ever accessed mental health services and her experience, she recalled:

When I was younger, I think 13 I was forced to take, forced, yeah not willing, I had to take therapy for a year. And for me, it just, it wasn't for me, because I don't like talking about my feelings. She kept asking me questions. And I didn't know why she's asking me questions. Like why, why is it any of your business? So now that I'm older, last year, during you know, maybe, I think it was last year, last year, I did access mental health services on campus. And so, I started seeing a therapist, but I went to one meeting. And it wasn't for me. I was like, No, no, I can deal with it. So yeah, it wasn't for me, just because I really, I don't like being exposed. And I don't like feeling vulnerable in front of strangers. I don't like it. It's not for me. And I think what I'm doing is OK, now like I don't like, I don't have any red flags in my mind, where I feel as if I need to go and see somebody and speak to them about it.

When Junior was asked about his thoughts on mental health, he stated "I don't have any thoughts on mental health". Even though he experienced an immense amount of violence throughout his life, he did not see the need to seek services. He stated: 
Because I have a strong mind and I know myself, I know... I'm not weak to certain things and know like I always think about things myself, but I know... I'm not affected by it because I know myself. I grow to think things out. I don't have a problem... I don't stress and I know how to control myself.

Junior was asked what his thoughts were on those who needed to access mental health services. He responded, "my thoughts are that if they are weak to it, then they need to seek help, but they just have to be more... they should try to be the strong one." He was asked what he meant by weak to which he replied, "If it's (violence) affecting them. they should speak up about it if they know it's affecting them or if they feel like... some type of way about it they should seek help about it."

When Kim was asked how she cares for herself, she responded with "I call my mom on the phone. I have my sisters; I have my children. You know, when I want somebody to talk to, I have my friends, you know, we laugh. We talk, you know, and they keep me strong positive." She was asked what her thoughts were regarding mental health, to which she replied "I never really think about mental health but... I never tried to hurt myself." When asked if she's ever accessed mental health services, she replied, “we don't have that in our country so, we never have people that give you that help. But here in Canada, yeah, that's different. If it was back in those days, and then I come here then I would have gotten the help but now". She said she wouldn't access mental health services, and when asked why not, she replied, "I'm not mental".

Despite the distancing from the concept of mental health, findings show that good mental health is essential to participants and their overall functioning. The participants seem to value being able to gauge their own levels of mental wellbeing and being able to always remain in control:

I always start off my day by putting myself first and by carving out that time that I need for me, definitely a lot of self-reflection, and taking inventory of my mind and my values and the steps that I'm taking that will help me move towards my dreams and my 
goals. And so what that looks like on in like a specific example level is working out not because I like to do it, but I know it'll help me in the long term, like help to fight diseases; cooking, because it keeps me occupied, and helps you make better healthy decisions. Reading, it helps me stay off the internet. (Mercy)

\section{Compassion for Others}

The participants also demonstrated compassion for others and the community around them. This compassion was the basis for one of the reasons they would access mental health services, with the hope of helping someone else. In addition to this, even through various forms of violence and witnessing it, they still find compassion for those around them. As Seebohm et al. (2010) have found, there is a strong cultural connection between the Black 'self' and the community.

In regard to caring for the community in terms of ensuring the safety of everyone, Junior spoke of a time he stepped in:

I see people chop up people and I go and I tell them, say, what they do is not right and everything come with a consequence. They basically sit down and ... they were feeling hype at the moment and the person diss them and they didn't know what they were doing and stuff. And I tell them like, you have to turn yourself into the police and do it right, like, and they did listen, and they go because the police was looking for them.

In regard to mental health, Kim and Mercy discussed the only reason why they would see the benefits of speaking with a licensed specialist:

Yeah, I would sit and talk to them, but I don't know what they offer. If they offer to listen, then I will talk. Yeah, (shakes head) my problems can change a lot of lives if I share it. (Kim)

I don't really like talking about my feelings, but I will, when I feel that it's necessary, or when I feel as if it will help somebody else. Like grow or like their situation, then I will speak about it. But like, in general, like, I'm not going to speak about my feelings all the time, especially if I don't know you and you're a stranger, even though you're certified. I still don't know you. I don't care. So, yeah. (Mercy) 


\section{Theme 4: Developed and Adapted Ways of Survival and Resilience}

By simply getting up and walking through a world that is mildly tolerant, Black bodies continue to resist and remain resilient. Kim and Junior shared their truths of growing up in a country torn, destroyed, and tarnish by colonization and the consequences suffered by those forced to grow up with the violence thereafter. Mercy spoke on her experience at a refugee camp with her family before coming to Canada at a young age. Yet, all three participants described their own form of survival and resilience through connection with their families, selfpreservation, their creation of understanding and development of life meanings, and spirituality.

\section{Connection with Family}

Connection with family is an essential component to having support and love through times of need and pain.

I would say my grandmother helped me to talk me out of it and stuff ...my grandma had an impact on my life that show me stuff and tell me about it when I share those things (violence) with her, so I don't feel like they (the pain) grow to be a part of me or... because she always there for me and taught me all of these things. (Junior)

Kim was asked if she shared her experience of violence with anyone, which she replied "I share to my children. I shared with my mother; I share it with my friends.” Kim also spoke on her mother's support after her jaw was broken, and she was released from the hospital:

I never knew my dad, I only knew my stepdad. So, growing up with one parent different from my stepdad. My mom have to do everything cause she had to take care of me, it was really hard. Then I had my two daughters at the time, so you know she had to care for me and the two children at the time. So it was really hard for her to take care the three of us plus herself, her husband, and her other two children. So, it was really hard. My mom, she was there to help me. 
Mercy maintained that her relationship and connection with her brothers were vital as

they navigated through the child welfare system after the death of her mother:

Family is important, like a part of my life goals, is leaving this world understanding and knowing that my brothers are taken care of. Sometimes, there are times of when we speak about our past, and like the traumatic experiences that we've had, and how we say that people always expect us to fall into the statistic of like, getting into drugs, jail, getting pregnant, because I'm Black, because I was in foster care all these, like, negatives. And so, my (big) brother and I like we speak about how you need to be mentally strong. And that when you're not that, like when we look, we pray about it. But also like, like, we're open with one another. So, I am lucky to have them there with me

\section{Self-Preservation}

Kim and Junior referred to 'work' and 'being able to provide for oneself' when asked how they care for themselves. When probed further, Junior names pool as a way of getting out of his head and engaging with his friends. Kim named being able to talk with her children, mother, and friends as a way of self-care. They both had the chance to enjoy human connection as a form of self-care. Mercy, on the other hand, stated:

I guess comparing my life to a typical student university life they have a place to go back home when they know if anything happens, they can just go back home to mom and dad. But for me, I personally don't feel like I have that choice. And I know that homelessness is something that can be very real to me, and I'm someone who doesn't like being dependent on others. And I work hard for what I have. And so, I know that I have to put in the work to get to where I want to be, and there is no, there is no fallback plan.

Like Mercy, Kim and Junior referred to working hard for what they have and being able

to practice self-preservation. Mercy, understandably, was the only participant that seemed

connected, yet distant from her family in order to be able to remain self-reliant.

I guess the you know, being one of the older siblings, you feel as if you have to set an example and imparts the experiences, the knowledge that you learn from your mistakes or from your experiences, and hope that your younger siblings will learn from it without having to make or recreate the same mistakes, which can be difficult, but also like being your own person, and knowing that your life is your own, and you also have to live for 
yourself. And you can't always live for other people, even if those people are family and they are very near and dear to you.

Yet, like Mercy, all participants spoke on not dwelling on the negative experiences too long as a form of self-perseveration because they cannot change the past.

If I dwell on it for too long, then I can go into a very dark place and a part of me a scare that I'll never be able to come back. So, I guess it's a form of self-preservation. I understand and I comprehend everything that's happened. But I don't feel that it's necessary to go into the emotions and the feelings of it or reliving that trip, like that trauma. (Mercy)

\section{Creation of Understanding}

Navigating through different life events usually changes values, beliefs, and a way of understanding for those who have to make meaning from it. This is seen and taken up as a way of coping and strategically protecting oneself from further harm in the future, or as a way of learning how to move forward and continue.

All participants took their experiences of violence as an opportunity to learn and grow.

From that day when I see that, I learned one thing from it like, never make your ego get the best of you. if I'm in some kind of a confrontation, if somebody confronted me, I always try to walk away or try not to talk to the person because that's the only way. It takes two to make argument. All of the violence I've witnessed is because two persons are in an argument and fighting about it. (Junior)

Growing up see my friends get hurt. See some of my family get hurt through violence like shooting, some of them get stabbed, some of them get chop, some of them put in jail, you know, so that makes me more stronger. Yeah. Focus more. I made different choices because I don't want to end up like them. I don't want to make because of their mistake make me go into jail or I have to hurt somebody, you know, so I learned by just watching them, sometimes people come and put trouble in my way. I will just walk away and smile. (Kim)

I just take things one day at a time. That is my story. And it's a, it's made me who I am today. And although if I could, I would change it, I can't and so I just need to make the best of my situation. I understand that the end of the day, I am resilience, and yeah, it's up to me to learn how to grow from that. And to live with that in my past. I've definitely become stronger through it. This is [a] silver lining: What doesn't kill you makes you stronger. It's, it's a testament to my resiliency as well. (Mercy) 


\section{Spirituality}

As another form of resilience, participants spoke about their faith and connection through spirituality. Junior connected spirituality with his grandmother who could predict of events through her dreams:

She (grandmother) would normally dream things before it happen. She is more like a Christian lady. She was a pastor. So, she dreamed I was riding my bicycle. And this guy hit me off my bicycle. She told me everything (up) to the car was right at my head and basically, that's the same thing I saw. The car was right at my head when they hit me and she tell me before and that's what happened. I couldn't believe. She most things she tell me about in life, I always watch out for them and she was the one that was always there for me.

Both Kim and Junior stated that they believed in God but junior elaborated:

I know there is a God. I know that but... I just don't know which religion to believe because it's all twisted. But I believe there's a higher being and you have to just pray to the higher being. Just like right and wrong, why would you do wrong when the outcome is violence?

Mercy also stated that she connects with a higher or greater being:

I don't believe that we were placed on this earth just to live and to die. I think everybody has a purpose, and that there's a greater or higher being, whatever you may call it, I don't know, Allah, God, doesn't matter. There's something bigger. And so, it's, like, looking at the things in my life and things I've gone through, I can't say that I made it out without some type of higher help. Because looking back I, like I saw where I could have been, and where I could have easily fall in and trips and died on multiple occasions...And so when it comes to spirituality, like it's, it's a personal thing. It's a relationship you have between yourself and whoever, whoever you believe in. But I also do believe that it's an important part of like, the human spirit and the human self to be complete. And to have that sense of purpose. And so almost sometimes find that strength, when you don't actually have the physical strength to keep on going.

Mercy also connected her sense of faith with the life of her mother

I didn't really get to know my mother, because I obviously lost her at a young age, but like coming from Africa, living in a refugee camp, giving birth to children, losing a child to death, dealing with, like evil spirits, or whatever coming to Canada, a new 
country, a new world, having to raise children, an abusive husband, and she still had the strength to care for us with love, and to instill in us like to work hard and to do well in school. And she did the best that she could. And she always like, took us to church, and she always believes strongly in God. And so, I believe that whatever brought her here and draw her this far. Who's to say that it can't take me like, all the way to the end?

It is evident that spirituality is taken up as a form of hope and purpose, and to make sense of life's meaning and encounters. Other forms of faith such as dreams or evil spirits shared through storytelling is also a form of knowledge sharing and resilience. 


\section{THEORETICAL ANALYSIS AND CRITICAL IMPLICATIONS}

Grounded theory is required to be 'grounded' in research and findings (Creswell, 2018). In order to ground this MRP in my findings, themes and subcategories were developed and the participants words were highlighted and presented in length and in authenticity. CRT allows for the centering of the lived experiences of people of colour and Symbolic Interactionism examines how human interactions and social environments develop meanings and understandings. My note, thoughts, and analysis were kept separate from the findings in a conscious effort to properly engage in the findings.

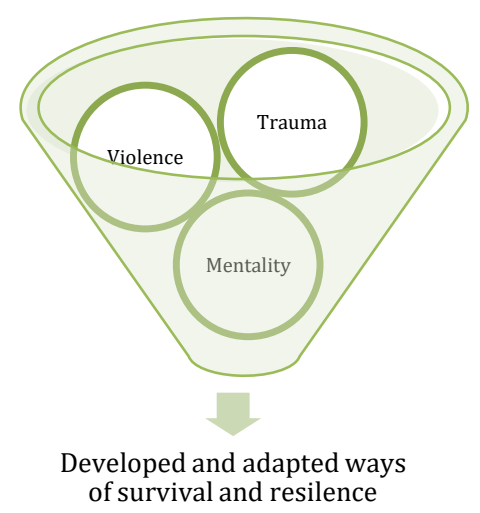

Figure 4: Critical Data Analysis

Using CRT and Symbolic Interactionism, I will next analyze the themes and subcategories in order to further explore the theory that due to exposure to continuous violence which starts at a young age, Black individuals are forced to adapt self-sufficient and selfregulated methods of survival, life understandings, and mental processes.

\section{Critical Analysis: Exposure to various forms of violence}


Through the themes and subcategories, it is clear that participants have experienced multiple circumstances that they have developed meaning from. CRT looks at the intersection and interaction of race and gender in relation to phenomena such as domestic violence. As previously mentioned, the only participant that did not speak on domestic violence was the participant who identified as a heterosexual male. The other two participants who spoke on domestic violence discussed the pain they experienced in their relationships or what they witnessed between their parents, which resulted in death. Findings shows that physical punishment or corporal punishment such as spanking, beatings was common in their households as a form of discipline. Participants saw these as a type of violent occurrence that was either a deterrent or a way of fear instilling. Violence was also witnessed as young as age 11 to age 17 years old where findings show that violence and weapons were normalized and a constant occurrence for participants growing up.

Either experienced physically or witnessed vicariously, participants developed meanings and life understandings from the violence around them. Interestingly, racism and discrimination did not seem to be as hurtful or as painful to discuss in comparison to the physical violence. Participants shared instances that they could recall of a time they felt noticeable or bluntly discriminated against. One participant, however, found it hard to recall an instance despite referring to herself as 'dark', yet also referred to herself as 'whitewashed'. This was used by the participant as she tried to explain to her classmates that she did not know anything about Black history month. This could be taken up as a way of distancing oneself from Blackness and all the implications that it takes up. It can be seen as a skin that the participants wear in order to navigate the space in which she occupies. It could be taken up as the need to hide and shield 
away from negative stereotypes. It is evident that more research is required on the topic of Black individuals referring to themselves as whitewashed.

\section{Critical Analysis: The Implications of Violence Experienced}

The findings show that violence had a lasting effect on the participants and how they processed their lived experiences. It was clear that depression was not an emotion that the participants felt comfortable discussing or identifying with. They did, however, discuss instances of loss and trauma. Death was a common occurrence for all three participants, but they explored it in different ways. For one participant, they discussed the loss that had impacted the way they were raised and nurtured. Mercy and her four siblings were brought up in the child foster care system, and thus did not have a system of support outside of her brothers. She had developed a way of navigation at the age of 11 in order to ensure she could keep her family connected such as 'playing the good girl' and 'not defending herself' in ways that still impacts her years later. She also discussed her loss in community and her connection to her identify and culture, which could explain how she developed her own identity, similar to what she believes to be 'whitewashed'.

Junior on the other hand did not identify or bring up thoughts of depression or loss; he discussed how he became sensitized to the violence around him. He equates the experiences as a way of life and a way of understanding. Yet, he did not believe it had an effect on him or his values. He had isolated himself from what was occurring around him, and thus living on a path that he considered 'straight' and 'positive'. 


\section{Critical Analysis: The Effects of Violence on Mental Health}

Mental health and mental illness are often times used interchangeably within the Black community. History of medicine and medical interventions, stigma within the community, and the need to be self-regulated are all factors to look into for further studies. The history between Black bodies and the medical field has been violent and deceptive throughout time especially around misdiagnosis and anesthesia. Current context cannot be separated from historical pass which is why more research must be done to examine how this has influenced the stigma in the Black community. Further research is also needed in order to examine why it is so important for Black folks to self-regulate and remain self-sufficient in regard to asking for help outside their immediate circles. In addition, how these impacts and informs their values and beliefs about themselves and about others who seek help.

Only Mercy had accessed a therapist or any service within the mental health sector. Although she believes that it is beneficial to have the perception of mental health shifting, she would not access further services in the future due to the fact that she does not like 'talking about her feelings' and that it was sharing her 'business'. The idea of a stranger knowing about your business is not a new concept that is exclusive to the Black community. It runs on the idea that what is done in the home, stays in the home and out of public gaze. Many communities are familiar with this ideology and its negative connotations.

Mental health services are also situated with the idea of 'madness' or 'instability'. When probed and the concept of mental health was fully overviewed by the researcher, participants insisted that they could process their experiences on their own. They used words such as 'strong' vs 'weak' to explain their thoughts. They insisted that they were strong enough not to be affected by circumstances or weak to the impacts. The presence of help is equated to weakness and thus 
results in the need for assistance. Kim was very reticent on the topic as she seemed to be trying not to say what she truly meant. She seemed offended when asked if she had ever accessed services and stated that it was because she was not 'mental' with a look that insinuated that I should not have asked the question because it was obvious. Although she stated that she wishes she had access to services at a younger age, she still would not access them now, which could be a consequence of stigma.

All participants cared for themselves in different ways whether it was done alone or with others. Furthermore, they spoke on their compassion for others and the opportunity to help someone else with their experiences. They were willing to share their experiences with others as a form of story-telling or shared healing in order to offer guidance and mentorship. These findings suggest that communal benefits of sharing stories of lived experiences would have to be an aspect or outcome of mental health services. Participants did not see healing in sitting down with someone in a room, talking about themselves, and then leaving after an hour. They wanted to be able to use their life experiences and share their knowledge with others which might present as mutual healing. This also highlights self-help groups as beneficial and requiring more research.

\section{Critical Analysis: Developed and Adapted Ways of Survival and Resilience}

Through experiences of pain, death, violence, and trauma, participants have developed their own way of coping and methods of survival. Black bodies and communities are beyond resilient in the ways they continue to resist, exist, and remain present. All participants spoke about their connection with their family as a way to stay grounded and access support. Family is an enormous support system that could shape and impact how we move through the world. 
Findings show that the presence of family members through life changing moments had an impact on participants and continue to be a factor in their mental health and resilience. The opportunity to share with those close to them, and to have support in the event of harm is an important aspect to note.

However, even with the connection to family, the ability to remove or dismiss the emotions associated with the trauma was important for participants. They did not want to stay present in the emotions, but rather move beyond it and forward. This is can be taken up as selfpreservation. Dwelling in the unchangeable circumstances of one's situations seemed to be a fear for participants, particularly Mercy. Participants have created ways of understanding and meanings from their encounter with death and experience. Through pain and heartache, they developed lessons in order to navigate their actions and ways of knowing. These ways of knowing highlights their resilience and their adapted ways of survival.

Spirituality was taken up and utilized as a form of resilience and a way of having 'faith'. Junior spoke of his beliefs in the accuracy of dreams and the ability it has to predict the future or what's to come. All participants believed in a greater being and a purpose to life. Mercy and Junior acknowledge that there are various religions and beliefs but align their beliefs within something 'bigger' or 'greater' than they are. Spirituality appeared to be connected to a loved one or a sense of family as well. Junior spoke of his grandmother who he admired, and Mercy spoke of her mother, who she wished she could have known. These could be ways of staying connected with the ones who we loved and have passed on. 


\section{CONCLUSIONS}

I understand that life isn't easy. And I've gone through some very dark places. And so, it's helped me look at life less narrow minded, because life is short. And the things you love and the things you always take for granted can be snatched so easily and quickly away from you. Slowly, the little problems, they don't even matter that much. Because at the end of the day, you're alive. And if you still have your loved ones, you're blessed, if you have a roof over your head, you're even more so blessed. And if you're walking and talking, you have breath in your lungs, then you are luckier than half of the people in this world. So, when it comes to my values, I'm grateful I wake up because life is fleeting and it can, it can disappear.

-Mercy

This quote beautifully summarizes the essence and the spirit of my three amazing participants as they told their stories. Despite the immense and various forms of violence they faced, they still manage to gather meaning and understanding from their encounters with violence. They still remained strong and resilient in how they walk through the world and how they continue to resist in their own ways.

Due to exposure to continuous violence that starts at a young age, Black individuals are forced to adapt self-sufficient and regulated methods of survival and life understandings. This theory, or way of understanding grounded in data (Creswell, 2018) is essential to why Symbolic Interactionism and Critical Race Theory had to be utilized in this study. Charmaz's (2018) constructive grounded theory approach allowed me to open space for diverse local worlds, multiple realities, and the complexities of particular worldviews and actions. By purposely highlighting participants' voices and allowing the research to be grounded in data and the words of the participants, I have actively engaged in challenging previous scholarship that has distorted and erased the experiences of Black families, communities, and individuals. More research and studies need to be done on various topics around violence, mental health, and resilience in the Black community. 
Symbolic Interactionism allowed for participants to explore and discuss how their human interactions with violence developed into meanings, interpretations, and life understandings. Through the development of codes, categories, and subcategories I was able to attribute meaning to the data. Critical Race Theory allowed the intersectionality of race, gender, sexual orientation, and age to all hold equivalent weight in experiences of Black individuals. Black bodies are victimized daily yet they continue to resist structural barriers and societal forces that aims for equality and colorblindness rather than equity and the centering of Black bodies. If we center Black bodies and voices, everyone benefits.

Thus, regardless of grounded theory as a methodological approach, while working in partnership with Black participants, race has to be centered and at the forefront. With CRT, I was able to interpret the perspectives and voices of the narratives that remain unacknowledged, distorted, and invalidated within research (Malagon, Huber, \& Velez, 2009). Both Symbolic Interactionism and CRT lens have allowed me to explore the lived experiences of Black individuals who have faced violence and trauma. This MRP demonstrates the various forms of violence, mental health stigma and hesitancy to access services, and resilience within Black individuals. Thus, more research and programs need to be developed in order to be able to understand the diverse levels of violence the Black community faces and how to limit the barriers they face internally and externally in regard to outside assistance. Self-help groups seems to align with the needs of this diverse communities, but more research and studies need to be done in regard to families and possibly the different roles loved ones might or can play in another's healing journey. 


\section{Ryerson \\ University}

\section{PARTICIPANTS NEEDED FOR RESEARCH IN 'The Impact of Violence and Trauma on Mental Health for Black Canadians"}

\section{Do You:}

$\checkmark$ Identify as Black, having a background from either the Caribbean or Africa

$\checkmark$ Have experienced various forms of violence and trauma

$\checkmark 18$ years or older

If you answered yes to the above noted questions you are invited to volunteer in this study. 3 Participants will be interviewed in order to explore the impact of violence and trauma in Black Canadians in regards to mental health. Your participation will involve a 1-2 hour interview.

If you are interested in participating in this study or for more information please contact: Karia Jones (MSW Student)

Ryerson School of Social Work

Email:kkjones@ryerson.ca

This research study has been reviewed and approved by the Ryerson University Research Ethics Board (2019-019) 


\title{
APPENDIX B. CONSENT FORM
}

Ryerson

University

\author{
Ryerson University \\ Consent Agreement
}

You are being invited to participate in a research study. Please read this consent form so that you understand what your participation will involve. Before you consent to participate, please ask any questions to ensure you understand what your participation will involve.

\section{The Impact of Violence and Trauma on the Mental Health of Black Canadians}

\section{INVESTIGATORS}

This research study is being conducted by Karia Jones, supervised by Professor Gordon Pon, from the School of Social Work at Ryerson University.

If you have any questions or concerns about the research, please feel free to contact:

$$
\begin{gathered}
\text { Karia Jones } \\
\text { kkjones@ ryerson.ca } \\
\text { Ryerson University } \\
\text { 350 Victoria Street }
\end{gathered}
$$

or

Gordon Pon

$$
\text { g2pon@ryerson.ca }
$$

Tel: 416-979-5000, ext. 4786

\section{PURPOSE OF THE STUDY}

The study is designed to explore the impact of violence and trauma experienced by Black Canadians in regard to mental health.

2 to 3 Participants will be recruited

Inclusion and Exclusion Criteria:

$\checkmark$ Participants must identify as Black, and having a background from either the Caribbean or Africa

$\checkmark$ Participants who have experienced violence in any form

$\checkmark$ Participants must be at least 18 years old and older 
I am completing this research in order to complete the major research paper (MRP) requirement of my Master of Social Work (MSW) degree (expected completion of program August 2019).

\section{WHAT PARTICIPATION MEANS}

If you volunteer to participate in this study, you will be asked to do the following things:

$\checkmark$ Attend a semi-structured interview, which will last between 1 to 2 hours.

$\checkmark$ Interviews will take place at Ryerson University within the MSW private lounge in order to ensure privacy, where they will be audio recorded.

$\checkmark$ Participants will be asked questions that involves sharing life experiences regarding violence such as:

- What forms of violence have you encountered in your life?

- What does resilience or caring for yourself look like?

$\checkmark$ The research findings will be available to participants upon completion of the transcribing of the auto-tapes. This transcription will be emailed to participants who wish to provide feedback.

\section{POTENTIAL BENEFITS}

$\checkmark$ This is beneficial for the black community in order to gain better understanding of the forms of violence we face and the impact it has on our mental health.

$\checkmark$ This provides an opportunity to share stories of challenges and hardships through act of sharing narratives.

$\checkmark$ Through sharing stories, this could provide a space for experiences to be acknowledged, validated, and valued.

I cannot guarantee, however, that you will receive any benefits from participating in this study.

\section{WHAT ARE THE POTENTIAL RISKS TO YOU AS A PARTICIPANT}

During the interview, there is a risk that the participants may experience psychological and emotional discomfort while they disclose experiences they've encountered in their lives. The risk of this happening is likely as it is often the black experience to face violence within and outside of our communities. Participants are at risk of feeling overwhelmed, anxious, and emotional drained while re-telling their stories. Due to the personal questions asked, participants may reflect on thoughts or memories that are emotionally exhausting during the interview. The researcher will expressly inform such participants that their participation is completely voluntary and that refusal to participate will not have any consequence for the nature of the alreadyexisting relationship between the two. Participants have until May 31, 2019 to withdraw their data and transcriptions.

\section{CONFIDENTIALITY}


Audio recordings are only used for the purpose of transcriptions, at which point they will be destroyed. Participants real name will not be used during the interview, while auto recording, or in the finished paper. Participants will be assigned numbers from 1 to 3. Participants' names will not be used in the recordings or final paper.

As a researcher, I have a duty to report information that may indicate harm to children. Under section 125 of the Child, Youth and Family Services Act every person who has reasonable grounds to suspect that a child is or may be in need of protection must promptly report the suspicion and the information upon which it is based to a Children's Aid Society.

\title{
DATA STORAGE
}

Signed consent forms, audio recorded interviews, interview transcriptions, and contact information will be collected. Signed consent forms will be kept in a secure locker only accessible by the researcher, which is kept in a secure room only accessible to other Social Work master's students. This information will be destroyed upon completion of this MRP. The audio recordings will be uploaded to password protected audio files that will be kept on Ryerson University Google drive. These audio files will be deleted once the transcriptions are completed which is anticipated to be within a week of the interview being audio-recorded. At this point, the transcriptions will be kept on Ryerson Google Drive up until the final draft of the paper is completed and submitted to the School of Social Work of Ryerson University - this is anticipated for mid-August 2019. Once the paper is submitted to the School of Social Work of Ryerson University the transcriptions will be deleted and destroyed.

\section{COMPENSATION FOR INJURY}

By agreeing to participate in this research, you are not giving up or waiving any legal right in the event that you are harmed during the research.

\section{VOLUNTARY PARTICIPATION AND WITHDRAWAL}

Participation in this study is completely voluntary. You can choose whether to be in this study or not. If any question makes you uncomfortable, you can skip that question. You may stop participating at any time and you may also choose to not have your data included in the study up until May 31, 2019. Your choice of whether or not to participate will not influence your future relations with Ryerson or the investigators, Karia Jones and Gordon Pon, who are involved in the research.

\section{QUESTIONS ABOUT THE STUDY}

If you have any questions about the research now, please ask. If you have questions later about the research, you may contact.

\author{
Karia Jones \\ kkjones@ryerson.ca
}




\section{Supervisor \\ Gordon Pon \\ g2pon@ ryerson.ca \\ 4169795000 ext. 4786}

This study has been reviewed and approved by the Ryerson University Research Ethics Board. If you have questions regarding your rights as a participant in this study please contact:

Research Ethics Board

c/o Office of the Vice President, Research and Innovation

Ryerson University

350 Victoria Street

Toronto, ON M5B 2K3

416-979-5042

rebchair@ryerson.ca

This research paper will be uploaded to the Ryerson Digital Depository. Please feel free to access the results at your own discretion: https://digital.library.ryerson.ca

\section{The Impact of Violence and Trauma on the Mental Health of Black Canadians}

\section{CONFIRMATION OF AGREEMENT:}

Your signature below indicates that you have read the information in this agreement and have had a chance to ask any questions you have about the study. Your signature also indicates that you agree to participate in the study and have been told that you can change your mind and withdraw your consent to participate at any time. You have been given a copy of this agreement. You have been told that by signing this consent agreement you are not giving up any of your legal rights.

Name of Participant (please print)

Signature of Participant

Date

\section{Audio-Recording}

I agree to be audio-recorded for the purposes of this study. I understand how these recordings will be stored and destroyed. 


\section{Feedback on Transcripts}

I agree to be contacted for the purposes of this study. I understand that audio recording will be transcribed and that I will have the opportunity to read my transcription and provide feedback.

Yes, I would like to be emailed a copy of my interview transcript

No, I would not like to be emailed a copy of my interview transcript

Email Address

Signature of Participant

Date 


\section{$\begin{array}{ll}\text { Ryerson } & \text { Research } \\ \text { Ethics Board }\end{array}$}

To: Karia Jones

Re: REB 2019-019: The impact of violence and acknowledgement of trauma on mental health on Black Canadians

Date:February 20, 2019

\section{Dear Karia Jones,}

The review of your protocol REB File REB 2019-019 is now complete. The project has been approved for a one year period. Please note that before proceeding with your project, compliance with other required University approvals/certifications, institutional requirements, or governmental authorizations may be required.

This approval may be extended after one year upon request. Please be advised that if the project is not renewed, approval will expire and no more research involving humans may take place. If this is a funded project, access to research funds may also be affected.

Please note that REB approval policies require that you adhere strictly to the protocol as last reviewed by the REB and that any modifications must be approved by the Board before they can be implemented. Adverse or unexpected events must be reported to the REB as soon as possible with an indication from the Principal Investigator as to how, in the view of the Principal Investigator, these events affect the continuation of the protocol.

Finally, if research subjects are in the care of a health facility, at a school, or other institution or community organization, it is the responsibility of the Principal Investigator to ensure that the ethical guidelines and approvals of those facilities or institutions are obtained and filed with the REB prior to the initiation of any research.

Please quote your REB file number (REB 2019-019) on future correspondence.

Congratulations and best of luck in conducting your research.

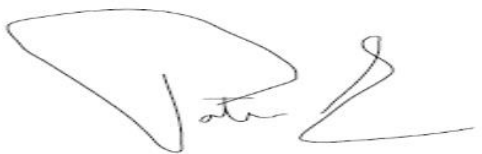

Dr. Patrizia Albanese, $\mathrm{PhD}$

Chair, Ryerson University Research Ethics Board

The Following protocol attachments have been reviewed and approved. 


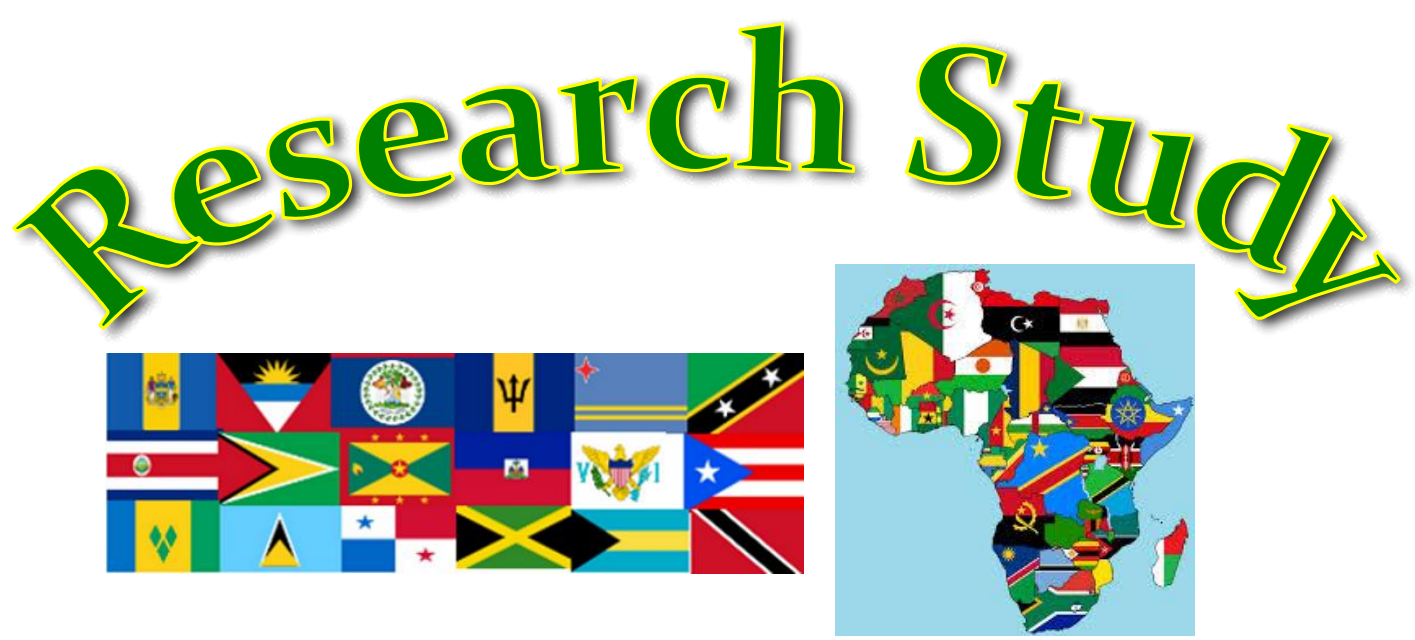

The Impact of Violence and Trauma on Mental Health for Black Canadians

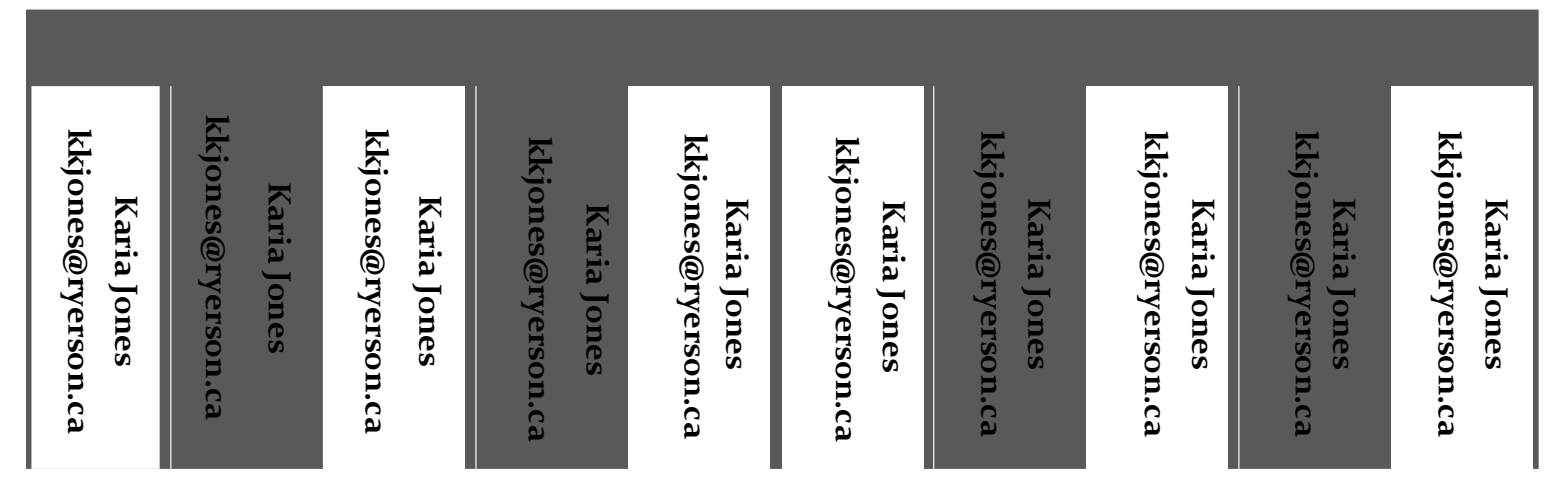




\section{REFERENCE LIST}

Alvidrez, J., Snowden, L. R., \& Kaiser, D. M. (2008). The experience of stigma among Black mental health consumers. Journal of Health Care for the Poor and Underserved, 19(3), 874-893. doi:10.1353/hpu.0.0058

Arthur, C., Hickling, F., Robertson-Hickling, H., Haynes-Robinson, T., Abel, W., \& Whitley, R. (2010). "Mad, sick, head nuh good": Mental illness stigma in Jamaican communities. Transcultural Psychiatry, 47(2), 252-275. doi:10.1177/1363461510368912

Brown, D. L., \& Tylka, T. L. (2010). Racial discrimination and resilience in African American young adults: examining racial socialization as a moderator. Journal of Black Psychology, 37(3), 259-285. doi:10.1177/0095798410390689

Bugeja, L., Dawson, M., Mcintyre, S., \& Walsh, C. (2013). Domestic/Family Violence Death Reviews. Trauma, Violence, \& Abuse,16(2), 179-187. doi:10.1177/1524838013517561

Chamberlain-Salaun, J., Mills, J., \& Usher, K. (2013). Linking symbolic interactionism and grounded theory Methods in a research design. SAGE Open, 3(3), 215824401350575. doi:10.1177/2158244013505757

Charmaz, K. (2018). Grounded theory methods in social justice research. In N. Denzin \& Y. Lincoln (Eds.). The Sage handbook of qualitative research ( $3^{\text {rd }}$ ed.) (pp.359-380). Thousand Oaks, California: Sage Publications.

Crenshaw, K. W. (1988). Race, reform, and retrenchment: Transformation and legitimation in antidiscrimination law. Harvard Law Review, 1331-1387.

Creswell, J.W.. (2013). Qualitative inquiry and research design: choosing among five traditions. Thousand Oaks, CA: Sage. (pp. 69-110). 
Creswell, J. W., \& Poth, C. N. (2018). Qualitative inquiry \& research design: Choosing among five approaches. Los Angeles: SAGE.

Delgado, R., \& Stefancic, J. (2017). "Introduction” and "Hallmark Critical Race Theory Themes" In Critical Race Theory: An Introduction. NYU Press. pp. 1-43

Ford, C. L., \& Airhihenbuwa, C. O. (2010). Critical race theory, race equity, and public health: toward antiracism praxis. American Journal of Public Health,100(S1), $\quad$ S30S35.

Foucault, Michel. 1980. Power/Knowledge: Selected Interviews and Other Writings 1972-1977, City? Publisher

Faulkner, S. S., Faulkner C. A. (2016). Research methods for social workers: A practice-based approach. New York: Oxford University Press

Gaylord-Harden, N. K., Dickson, D., \& Pierre, C. (2016). Profiles of community violence exposure among African American youth: An examination of desensitization to violence using latent class analysis. Journal of Interpersonal Violence, 31(11), 2077-2101. doi: $10.1177 / 0886260515572474$

Jackson, B. A. (2018). Beyond the cool pose: Black men and emotion management strategies. Sociology Compass, 12(4). doi:10.1111/soc4.12569

Jeon, Y. (2004). The application of grounded theory and symbolic interactionism. Scandinavian Journal of Caring Sciences, 18(3), 249-256. doi:10.1111/j.1471-6712.2004.00287.x

Klunklin, A., \& Greenwood, J. (2006). Symbolic interactionism in grounded theory studies: women surviving with HIV/AIDS in rural northern Thailand. Journal of the Association of Nurses in AIDS Care, 17(5), 32-41. doi:10.1016/j.jana.2006.07.005

Lacey, K. K., West, C. M., Matusko, N., \& Jackson, J. S. (2015). Prevalence and factors 
associated with severe physical intimate partner violence among U.S. Black women. Violence Against Women, 22(6), 651-670. doi:10.1177/1077801215610014

Landson-Billings, G. (2003). Racialized discourses and ethnic epistemologies. In N. Denzin \& Y. Lincoln (Eds.). Handbook of qualitative research. California: Sage. Malagon, M. C., Huber, L. P., \& Velez, V. N. (2009, November). Our Experiences, Our Methods: Using Grounded Theory to Inform a Critical Race Theory Methodology. Retrieved from https://digitalcommons.law.seattleu.edu/sjsj/vol8/iss1/10/ Maynard, R. (2017). “Devaluing Black Life, Demonizing Black Bodies: Anti-Blackness from Slavery to Segregation." Policing Black lives: State violence in Canada from slavery to the present. City? Fernwood Publishing. pp. 20-49

Mullaly, B. (2002). Challenging oppression and confronting privilege. Don Mills, ON: Oxford University Press

Newman, B. (2008). Challenging convention: Symbolic interactionism and grounded theory. Collegian, 15(3), 103-107. doi:10.1016/j.colegn.2007.12.002 Neuman, W. L. (2006). Social research methods: Qualitative and quantitative approaches. Boston: Pearson/AandB.

Nugent, N. R., Koenen, K. C., \& Bradley, B. (2012). Heterogeneity of posttraumatic stress symptoms in a highly traumatized low income, urban, African American sample. Journal of Psychiatric Research, 46(12), 1576-1583.

doi:10.1016/j.jpsychires.2012.07.012

Pachter, L. M., Caldwell, C. H., Jackson, J. S., \& Bernstein, B. A. (2017). Discrimination and mental health in a representative sample of African-American and Afro-Caribbean youth. Journal of Racial and Ethnic Health Disparities, 5(4), 831-837. 
doi:10.1007/s40615-017-0428-z

Padgett, D. K. (2017). Qualitative methods in social work research. Los Angeles: Sage.

Pate, M., \& Gould, L. A. (2014). Corporal punishment around the world. Retrieved from https://ebookcentral-proquest-com.ezproxy.lib.ryerson.ca

Paxton, K. C., Robinson, W. L., Shah, S., \& Schoeny, M. E. (2004). Psychological distress for African-American adolescent males: exposure to community violence and social support as factors. Child Psychiatry and Human Development, 34(4), 281-295. doi:10.1023/b:chud.0000020680.67029.4f

Pieterse, A. L., Nevile, H. A., Todd, N. R., \& Carter, R. T. (2012). Perceived racism and mental health among Black American adults: A meta-analytic review. Journal of Counseling Psychology, 59(1), 1-19. doi:10.1037/a0026208

Pon, G., Giwa, S., Razack, N. (2016). Insert chapter title? Diversity and Social Work in Canada. Don Mills: Oxford University Press. (pp. 38-58).

Ray, V. E., Randolph, A., Underhill, M., \& Luke, D. (2017). Critical race theory, Afro pessimism, and racial progress narratives. Sociology of Race and Ethnicity, 3(2), 147158.

Seebohm, P., Munn-Giddings, C., \& Brewer, P. (2010). Whats in a name? A discussion paper on the labels and location of self-organising community groups, with particular reference to mental health and Black groups. Mental Health and Social Inclusion, 14(3), 23-29. doi:10.5042/mhsi.2010.0441

Smith, J. R. (2015). Unequal burdens of loss: examining the frequency and timing of homicide deaths experienced by young Black men across the life course. American Journal of Public Health, 105(S3). doi:10.2105/ajph.2014.302535

Smith, J. R., \& Patton, D. U. (2016). Posttraumatic stress symptoms in context: Examining 
trauma responses to violent exposures and homicide death among Black males in urban neighborhoods. American Journal of Orthopsychiatry, 86(2), 212-223.

doi:10.1037/ort0000101

Taylor, R. J., Nguyen, A. W., Sinkewicz, M., Joe, S., \& Chatters, L. M. (2012). Comorbid mood and anxiety disorders, suicidal behavior, and substance abuse among Black Caribbeans in the U.S.A. Journal of African American Studies, 17(4), 409-425. doi:10.1007/s12111$012-9237-y$

Watkins, D. C., Walker, R. L., \& Griffith, D. M. (2010). A meta-study of Black male mental health and well-being. Journal of Black Psychology, 36(3), 303-330. doi:10.1177/0095798409353756

West, C. M. (2004). Black women and intimate partner violence. Journal of Interpersonal Violence, 19(12), 1487-1493. doi:10.1177/0886260504269700

Williams, D. R., Haile, R., González, H. M., Neighbors, H., Baser, R., \& Jackson, J. S. (2007). The mental health of Black Caribbean immigrants: results from the national survey of American life. American Journal of Public Health, 97(1), 52-59. doi:10.2105/ajph.2006.088211

Yee, J. (2005). Critical anti-racism praxis: The concept of whiteness implicated. Social work, a critical turn, 87-104. 
